\title{
An operational measure of physician lifelong learning: its development, components and preliminary psychometric data
}

\author{
MOHAMMADREZA HOJAT, THOMAS J. NASCA, JAMES B. ERDMANN, \\ ANTHONY J. FRISBY, J. JON VELOSKI \& JOSEPH S. GONNELLA \\ Center for Research in Medical Education and Health Care, \\ Jefferson Medical College of Thomas Jefferson University, Philadelphia, Pennsylvania, USA
}

\begin{abstract}
SUMMARY Despite the emphasis placed on physicians' lifelong learning, no psychometrically sound instrument has been developed to provide an operational measure of the concept and its components among physicians. The authors designed this study to develop a tool for measuring physician lifelong learning, to identify its underlying components and to assess its psychometric properties. A 37-item questionnaire was developed, based on a review of literature and the results of two pilot studies. Psychometric analyses of the responses of 160 physicians identified 19 items that were included in the Fefferson Scale of Physician Lifelong Learning. Factor analysis of the 19 items showed five meaningful factors that were consistent with the definition and major features of lifelong learning. They were 'need recognition', 'research endeavor', 'self-initiation', 'technical skills' and 'personal motivation'. The method of contrasted groups provided evidence in support of the validity of the five factors. The factors' reliability was assessed by coefficient alpha. It is concluded that lifelong learning is a multifaceted concept, and its operational measure is feasible for evaluating different educational programs and for studying group differences among physicians.
\end{abstract}

\section{Introduction}

Medical education is a learning process that begins in medical school, extends into graduate medical education, and continues throughout physicians' professional life (AAMC, 1999). The importance of preparing medical students to become lifelong learners has been evident in each of the three reports of the AAMC's Medical School Objectives Project (MSOP) (www.aamc.org/meded/msop). As recommended in the MSOP, medical students should develop skills and motivation "to engage in lifelong learning to stay abreast of relevant scientific advances" (www.aamc. $\mathrm{org} / \mathrm{meded} / \mathrm{msop} / \mathrm{report} 1 . \mathrm{htm}$ [p. 5]). In the practice of medicine, a commitment to rigorous learning throughout professional life has been described as an important element of 'professionalism' (Nelson, 1998).

Various terms such as self-directed learning, self-educative approach, self-initiative learning, active learning, independent learning, contextual learning, continuing education and distance learning have been included in one terminological basket under the rubric of lifelong learning. Although these terms may share some common features, it would be difficult operationally to measure lifelong learning without identifying its unique features (Miflin et al., 1999). According to some researchers, the key features of lifelong learning include personal motivation, recognition of needs that prompts an active search for knowledge, and information-seeking skills (Knowles, 1975; Bligh, 1993). Candy (1991) indicated that lifelong learning education equips people with competences and skills to continue their self-education beyond the completion of their formal schooling.

Despite the emphasis placed on physicians' lifelong learning, no universally accepted definition of the term has been proposed, and no psychometrically sound tool has been developed to provide an operational measure of the concept and its empirically derived components among physicians. However, Guglielmino developed a Self-Directed Learning Readiness Scale (SDLRS) (Guglielmino, 1977) that contains 58 Likert-type items (a sample item is: 'I love to learn').

A short version of the SDLRS, which includes only 28 items of the original scale, was prepared by Bligh (1993 [SSDLRS]). Frisby (1991) administered the SDLRS to medical students, and found that students' self-directed learning scores did not increase during medical school, and that medical students were similar to other students on this scale.

Another scale to identify predictors of self-directed learning was developed by Oddi (1986), but subsequent validity studies did not produce consistent supportive results (Six, 1989; Oddi, 1990).

Among the issues related to lifelong learning are some unverified assumptions that the type of educational curriculum can influence lifelong learning habits. For example, Mennin and his colleagues surveyed two groups of physicians who pursued either a conventional or a problem-based learning (PBL) track in the first two years of medical school. Graduates of the PBL curriculum reported that they were more motivated to continue their education (Mennin et al., 1996). Blumberg (2000) reported that students following PBL curricula were likely to use self-directed learning skills. Conversely, McGowan (1995) found no difference in the perceptions of lifelong learning between graduates of PBL and a conventional curriculum. Results of these studies are problematic because a psychometrically sound instrument for measuring lifelong learning does not exist.

Correspondence: Dr M. Hojat, Center for Research in Medical Education and Health Care, Jefferson Medical College of Thomas Jefferson University, 1025 Walnut Street, Philadelphia, PA 19107, USA. Email: Mohammadreza.Hojat@Jefferson.edu 
In addition, research design problems such as selfselection, rather than random assignment of students into different programs, could seriously confound the outcomes. It can be intuitively assumed that a curriculum requiring students to utilize certain information-seeking skills fosters lifelong learning habits, or would be attractive to a student with a predisposition toward lifelong self-directed learning However, convincing evidence is not really available to support this contention (Colliver, 2000; Schmidt, 2000). Furthermore, evidence is needed to confirm that learning skills developed in medical school can be transferred to professional practice (Schmidt, 2000).

\section{Definition}

Lifelong learning is a complex concept as reflected in the following definition:

Lifelong learning is the development of human potential through a continuously supportive process which stimulates and empowers individuals to acquire all the knowledge, values, skills and understanding they will require throughout their lifetimes with confidence, creativity and enjoyment in all roles, circumstances and environments. (Aspin et al., 2001, p. 592; see also Longworth \& Davies, 1996)

This is a broad definition. It is difficult to develop an operational measure to address all of the concepts described in this definition (e.g. human potential, continuously supportive process, stimulating, empowering, knowledge, values, skills, understanding, confidence, creativity and enjoyment). For the purpose of this study, based on a reading of the literature and panel discussions in our pilot studies, we defined lifelong learning as a concept involving a set of self-initiated activities (behavioral aspect) and information-seeking skills (capabilities) that are activated in individuals with a sustained motivation (predisposition) to learn and the ability to recognize their own learning needs (cognitive aspect). The four keywords in this definition that are frequently described in the lifelong learning literature are given in italics.

\section{Study purpose}

This study was designed to develop a scale of lifelong learning among physicians, to identify its underlying components and to assess its psychometric properties.

\section{Methods}

\section{Study participants}

Participants included 160 physicians affiliated with the Jefferson Health System (126 men, 34 women). Respondents' ages ranged from 29 to 82 years (mean = 46.9 , standard deviation $=10.9$ years). Respondents' specialties were as follow: $33 \%$ primary care, $19 \%$ surgery and subspecialties, $15 \%$ hospital based, $8 \%$ obstetrics/gynecology, $4 \%$ psychiatry, and the rest in other specialties. They received their medical degrees between 1944 and 1997.

\section{Instrument}

The instrument was developed based on a review of the literature and on two pilot studies by using the rational scale methodology (Reiter-Palmon \& Connelly, 2000) and a variation of the Delphi technique (Cyphert \& Gant, 1970). In the first pilot study, 12 Jefferson Medical College faculty, who were part of the Dean's medical education research team and were involved in medical education research, met several times to draft a definition of lifelong learning and its associated features based on their review and discussion of relevant literature. Each was asked to draft statements to describe features of lifelong learning consistent with their reading of the literature. Forty statements were submitted by using the rational scale method of theory-based item selection (Reiter-Palmon \& Connelly, 2000). Over three iterations, the faculty members were asked to judge the statements' content validity and to make appropriate modifications, additions or deletions. After incorporating their suggestions, the first draft of the instrument was developed. It consisted of 40 Likerttype items (on a four-point scale from Strongly Disagree $=1$ to Strongly Agree $=4$ ).

In a second pilot study, by using a variation of the Delphi technique (Cyphert \& Gant, 1970), 28 Jefferson faculty members were asked to independently review the 40 -item questionnaire. These faculty members were chosen from different departments and were known to the investigators for their involvement in medical education research. They were asked to respond to each item and specify the relevance, clarity and importance of each in measuring lifelong learning among physicians. Based on the respondents' feedback, we revised the questionnaire to include 37 items in the version used in the present study.

Included in the questionnaire were questions about the respondents' gender, age, specialty, the year their MD degree was awarded, plus additional questions about research, teaching and other professional activities. Respondents were also asked to rate themselves on a 10-point global scale of lifelong learning $(1=$ not committed to lifelong learning at all, $10=$ a tireless advocate of lifelong learning) intended to be used as a criterion measure for the validity study.

\section{Procedures}

After obtaining approval from the Institutional Review Board (IRB), the questionnaire was mailed to 373 physicians in the Jefferson Health System, which is affiliated with Thomas Jefferson University Hospital and Jefferson Medical College in the greater Philadelphia region. This random sample represented one-third of all physicians in the Jefferson Health System. Because of the pilot nature of the study, no follow-up reminder was sent, and 160 completed questionnaires were received ( $43 \%$ response rate).

\section{Statistical analyses}

Correlational methods, factor analysis (principal component, varimax rotation, using the matrix of inter-item correlations), and $t$-test were used. Estimates of effect size were also calculated for comparisons between means to examine the practical (clinical) significance of the differences. 


\section{Results}

We retained those items in the final version of the questionnaire that met each of the following inclusion criteria:

(1) A statistically significant correlation $(r>0.20, p<0.05)$ with the external criterion measure (10-point global scale of lifelong learning).

(2) A rotated factor loading coefficient greater than 0.40 on the first two grand factors that were extracted from factor analysis of the 37 items. The eigenvalues for the other factors dropped drastically after extraction of the two grand factors.

Nineteen items met the inclusion criteria for the fefferson Scale of Lifelong Learning (a copy can be obtained from the authors).

\section{Underlying components}

Data on the 19 items were subjected to an exploratory factor analysis to examine the underlying components of the scale. The exploratory factor analysis yielded five meaningful factors, each with an eigenvalue greater than one. These five factors accounted for $60 \%$ of the total variance before rotation $(27 \%, 14 \%, 7 \%, 6 \%$ and $6 \%$, accounted for by factors $1,2,3,4$ and 5 , respectively)

Examining the contents of the items with factor coefficients greater than 0.40 on factor 1 suggests that this factor can be considered as a construct involving 'need recognition'. Six items had coefficients greater than 0.40 on this factor. The item with the highest coefficient (0.76) on this factor was: 'I would fall behind if I stop learning about new developments in my profession.'

Factor 2 was a construct of 'research endeavor' based on the contents of the four items with coefficients greater than 0.40 on this factor. The item with the highest coefficient (0.87) on this factor was: 'I give on the average at least one presentation at professional meetings in every given year.'

Factor 3, a construct of 'self-initiated or self-directed learning activities' consisted of four items with coefficients greater than 0.40 . The item with the highest factor coefficient (0.71) under this factor was: 'I review professional journals every week.'

Factor 4 was a construct involving 'technical or computer skills'. Three items had coefficients greater than 0.40 on this factor. The item with the highest coefficient (0.83) was: 'I search computer databases (e.g. MEDLINE) to find out about new developments in my field of medicine.'

Finally, factor 5, a construct involving 'motivation', comprised three items that had factor coefficients greater than 0.40. The item with the highest coefficient (0.69) on this factor was: 'Searching for an answer to a question is, in and by itself, rewarding.'

These factors are conceptually relevant to the notion of lifelong learning and its unique features described by others (Knowles, 1975; Candy, 1991; Bligh, 1993; Jennet \& Swanson, 1994; Nelson, 1998). The factors are also consistent with the competences and attributes of selfdirected learning such as skills for information retrieval (e.g. computer skills), motivation and self-initiation described by Candy (1991) and identification of learning needs (e.g. need recognition) described by Jennett \& Swanson (1994). These findings are consistent with the features of lifelong learning described in the literature and provide support for the construct validity of the scale.

\section{Validation by contrasted groups}

We calculated factor scores and compared the mean of factor scores for men and women and for physicians contrasted by their 'yes' or 'no' responses to questions about their involvement in research, teaching and other professional activities. These activities and the statistical summary results are presented in Table 1. Statistical significance was determined by $t$-test. The effect size estimates for mean differences are reported in the table. An effect size estimate is a scale-free index that shows the degree to which the study results are of practical (clinical) importance (Cohen, 1987; Hojat \& Xu, in press). According to the operational definitions suggested by Cohen (1987) mean differences with an effect size estimate around or below 0.20 are considered small and negligible, those around 0.50 are moderate, and those with an effect size estimate greater than 0.80 are large and of practical (clinical) importance (Cohen, 1987, pp. 19-74).

As shown in the table, no significant difference was found between men and women on the components of lifelong learning, except for 'research endeavor' where men outscored women (effect size $=0.50$ ). This is consistent with previous findings that showed male physicians reporting more involvement with research activities than female physicians (Hojat et al., 1995). This can be considered as evidence in support of the validity of the 'research endeavor' component of the lifelong learning scale.

Data reported in Table 1 also indicate that physicians who published papers, presented research findings at professional meetings or collaborated in the conduct of research obtained significantly higher mean scores on each of the five factors compared with those who were not involved in these types of activities. The largest effect size estimates were obtained for the 'research endeavor' factor (effect sizes are 1.6 for publishing papers, 1.5 for presenting papers and 1.4 for collaboration in research). The large magnitude of these effect size estimates indicates that each of the factors of lifelong learning in general, and the 'research endeavor' component in particular, is strongly associated with research activities.

The 'self-initiation/self-directed' component of lifelong learning is also associated with relevant activities such as receiving research grants (effect size $=1.2$ ), receiving professional awards or honors (effect size $=0.3$ ), journal editorial activities (effect size $=0.40$ ), and serving as a journal reviewer (effect size $=0.40$ )

The 'technical/computer skills' component of lifelong learning was also associated with relevant activities such as sharing in the development of medical/surgical procedures (effect size $=0.70$ ), serving as a journal reviewer (effect size $=0.70$ ), receiving research grants (effect size $=0.70$ ), and receiving professional awards (effect size $=0.40$ ).

The 'personal motivation' component of lifelong learning showed a strong link to holding office in national professional organizations (effect size $=0.60$ ), journal editorial activities (effect size $=0.6$ ), serving as a manuscript reviewer (effect size $=0.50$ ), and presenting patient education or research 
Table 1. Effect size estimates for mean differences on factor scores ${ }^{a}$ of the Jefferson Scale of Physician Lifelong Learning by gender and professional activities.

\begin{tabular}{|c|c|c|c|c|c|c|}
\hline & & \multicolumn{5}{|c|}{ Lifelong learning factors } \\
\hline & & $\begin{array}{c}1 \\
\text { Need } \\
\text { recognition }\end{array}$ & $\begin{array}{c}2 \\
\text { Research } \\
\text { endeavor }\end{array}$ & $\begin{array}{l}3 \\
\text { Self- } \\
\text { initiation }\end{array}$ & $\begin{array}{c}4 \\
\text { Technical/ } \\
\text { computer skills }\end{array}$ & $\begin{array}{c}5 \\
\text { Personal } \\
\text { motivation }\end{array}$ \\
\hline Gender: men $=126$; women $=34$ & & -0.1 & $0.5^{\star \star}$ & 0.2 & 0.2 & 0 \\
\hline Professional activities & $\begin{array}{l}\text { No. of 'Yes' } \\
\text { responses }\end{array}$ & & & & & \\
\hline Published papers in professional journals & 99 & $0.9^{\star \star}$ & $1.6^{\star \star}$ & $0.7^{\star \star}$ & $1.2^{\star \star}$ & $0.7^{\star \star}$ \\
\hline Presented papers in professional meetings & 91 & $0.3^{\star}$ & $1.5^{\star \star}$ & $0.3^{\star}$ & $0.9^{\star \star}$ & $0.7^{\star \star}$ \\
\hline Collaborated in the conduct of research & 99 & $0.3^{\star}$ & $1.4^{\star \star}$ & $0.4^{\star}$ & $0.8^{\star \star}$ & $0.5^{\star \star}$ \\
\hline Served on professional committees & 105 & 0.2 & $0.6^{\star \star}$ & 0.1 & 0.2 & 0.2 \\
\hline Held office in national professional organization & 32 & 0.1 & $0.8^{\star \star}$ & 0.2 & 0.2 & $0.6^{\star \star}$ \\
\hline $\begin{array}{l}\text { Presented patient education/research } \\
\text { findings in newspapers/radio/TV/community groups }\end{array}$ & 62 & 0.1 & $0.7^{\star \star}$ & $0.3^{\star}$ & 0.1 & $0.3^{\star}$ \\
\hline Taught medical students/residents & 140 & 0.2 & 0.2 & 0.7 & 0.6 & 0.3 \\
\hline Received research grant & 49 & 0.1 & $1.2^{\star \star}$ & $0.5^{\star \star}$ & $0.7^{\star \star}$ & 0.1 \\
\hline Received professional awards/honors & 69 & 0.0 & $0.8^{\star \star}$ & $0.3^{\star}$ & $0.4^{\star}$ & $0.3^{\star}$ \\
\hline Shared in the development of medical/surgical procedures & 37 & 0.1 & $1.2^{\star \star}$ & $0.3^{\star}$ & $0.7^{\star \star}$ & $0.3^{\star}$ \\
\hline Served as editor/on editorial board of a professional journal & 29 & 0.1 & $1.0 \star \star$ & $0.4^{\star}$ & $0.4^{\star}$ & $0.6^{\star \star}$ \\
\hline Served as a reviewer of a professional journal & 64 & 0.2 & $1.2^{\star \star}$ & $0.4^{\star}$ & $0.7^{\star \star}$ & $0.5^{\star \star}$ \\
\hline
\end{tabular}

Notes: ${ }^{\text {a }}$ The statistical significance of the differences was determined by $t$-test. Effect size estimates for gender differences were calculated by the following formula: $\left(\mathrm{Mean}_{\mathrm{men}}-\mathrm{Mean}_{\text {women }}\right) /$ pooled standard deviation, and effect size estimates for the listed activities were calculated by the following formula: $\left(\mathrm{Mean}_{\mathrm{yes}}-\mathrm{Mean}_{\mathrm{no}}\right) /$ pooled standard deviation. ${ }^{\star \star} p<0.01 .{ }^{\star} p<0.05$.

findings in the public media or community groups (effect size $=0.30$ ). The aforementioned results by the method of contrasting groups (Anastasi, 1976) are consistent with our expectations about lifelong learning activities, and provide evidence for the validity of the scale's underlying components.

\section{Internal consistency reliability}

The values of Cronbach's coefficient alpha calculated for each component of the lifelong learning scale were 0.99 (for the 'need recognition' components), 0.82 (for 'research endeavor'), 0.75 (for 'self-initiation'), 0.74 (for the 'technical skills' component), and 0.65 (for 'personal motivation'). The alpha for the entire scale (19 items) was 0.93 . Coefficients of these magnitudes are in the acceptable range for educational and psychological scales and, therefore, provide support for the internal consistency reliability of the components, and for the total scores on the Jefferson Scale of Physician Lifelong Learning.

\section{Conclusions, limitations, implementation and future research}

Lifelong learning has become one of the most frequently discussed concepts in professional education, and is based on the notion that every professional person should be actively encouraged, motivated and able to learn throughout his or her professional life (Mckenzie, 2001). In this study we attempted to conceptualize the multidimensional and complex notion of lifelong learning and develop an instrument to measure it operationally, specifically among physicians. To the best of our knowledge, this is the first instrument for measuring lifelong learning developed specifically for physicians with supporting psychometric evidence.

The results of this study suggest that it is feasible to develop an operational tool to measure lifelong learning among physicians. The results of exploratory factor analysis indicate that lifelong learning is a multidimensional concept consisting of at least five underlying features of 'need recognition' (cognitive aspect), 'research endeavor' (capabilities), 'self-initiation/self-directed learning' (behavioral aspect) 'technical/computer skills' (skills), and 'personal motivation' (predisposition). These features are consistent with the definition of lifelong learning that we proposed and are conceptually relevant to the notion, activities and outcomes of lifelong learning.

This preliminary study is limited by the small sample size representing mostly academic physicians. Also, the validity of the extracted factors should be examined by using a more specific and relevant external criterion measure. Despite these limitations, preliminary data in this study support some important psychometric aspects of the Jefferson Scale of Physician Lifelong Learning (e.g. construct validity, criterion-related validity, internal consistency reliability). Further research with a larger and more representative sample of physicians is needed to confirm the factorial structure of the scale and to examine the validity of each extracted factor by using appropriate external criterion measures. It is also desirable to provide evidence in support of the scale's testretest reliability, and would be useful to construct a norm table (e.g. percentile score distribution) for comparative purposes. We plan to conduct further research to address these issues. 
By providing further evidence in support of factorial structure and other psychometrics of the Jefferson Scale of Lifelong Learning, this scale will become a valuable tool for research in physician lifelong learning and for evaluating medical education programs.

\section{Acknowledgment}

The continuation of this project will be funded (in part) by a National Board of Medical Examiners (NBME) Edward J. Stemmler, MD Medical Education Research Fund grant. The project does not necessarily reflect NBME policy, and NBME support provides no official endorsement. The authors would like to thank the following Jefferson Medical College faculty members for their contribution to the initial pilot study of this project: Timothy Brigham, PhD, Clara A. Callahan, MD, Edward Christian, PhD, Cynthia Cilber, MD, Karen Glaser, PhD, David Paskin, MD, Charles Pohl, $\mathrm{MD}$, Salvatore Mangione, MD, and Susan Rattner, MD. They would also like to thank Dorissa Bolinski for her editorial assistance.

\section{Notes on contributors}

Mohammadreza Hojat, PhD is Research Professor of Psychiatry and Human Behavior, and Director of the Jefferson Longitudinal Study of Medical Education.

Thomas J. Nasca, MD is Dean, Jefferson Medical College, and Senior Vice President, Thomas Jefferson University.

James B. Erdmann, PhD is dean, Jefferson College of Health Professions of Thomas Jefferson University.

Anthony J. Frisby, PhD is Director of Education Services, Academic Information Services and Research.

J. Jon Veloski, MS is Director of the Medical Education Research Division of the Center for Research in Medical Education and Health Care.

Joseph S. Gonnella, MD is Dean Emeritus, Distinguished Professor of Medicine, and the founder and Director of the Center for Research in Medical Education and Health Care.

\section{References}

AAMC (1999) Contemporary issues in medicine-medical informatics and population health: Report II of the Medical School Objectives Project, Academic Medicine, 74, pp. 130-141.

Anastasi , A. (1976) Psychological Testing (New York, Macmillan).

Aspin, D., Chapman, J., Hatton, M. \& Sawano,Y. (Eds) (2001) International Handbook of Lifelong Learning (parts $1 \& 2$ ) (London, Kluwer).

BLIGH, J. (1993) The S-SDLRS: a short questionnaire about self-directed learning, Postgraduate Education for General Practice, 4, pp. 121-125.

Blumberg, P. (2000) Evaluating evidence that problem-based learners are self-directed learners: a review of the literature, in: D.H. Evenson \& C.E. Hmelo (Eds) Problem-Based Learning: A Research Perspective on Learning Interactions, pp.199-226 (MAHWAH, NJ, Lawrence Erlbaum).

CANDY, P.C. (1991) Self-Direction for Life-Long Learning: A Comprehensive Guide to Theory and Practice (San Francisco, Jossey-Bass).

Cohen, J. (1987) Statistical Power Analysis for Behavioral Sciences (Hillsdale, NJ, Lawrence Erlbaum).
Colliver , J.A. (2000) Effectiveness of problem-based learning curricula: research and theory, Academic Medicine, 75, pp. 259-266.

CypheRT, F.R. \& GaNT, W.L. (1970) The Delphi technique: a tool for collecting opinions in teacher education, fournal of Teacher Education, 31, pp. 417-425.

FRISBY, A.J. (1991) Self-directed learning readiness in medical students at The Ohio State University [Doctoral dissertation, The Ohio State University, 1991], Dissertation Abstracts International, 52, 2896 A.

Guglielmino, L.M. (1977) Development of the self-directed learning readiness scale. [Doctoral dissertation, University of Minnesota, 1977], Dissertation Abstracts International, 38, 6467A.

Hojat, M., Gonnella, J.S. \& XU, G.(1995) Gender comparisons of young physicians' perceptions of heir medical education, professional life, and practice: a follow-up study of Jefferson Medical College graduates, Academic Medicine, 70, pp. 305-312.

Нолат, M. \& XU, G. (in press) A visitor's guide to effect sizes: statistical significance versus practical (clinical) importance of research findings, Advances in Health Sciences Education

[http://www.aamc.org/meded/msop/report1.htm (for Report 1), http:// www.aamc.org/meded/msop/report2.htm (for Report 2), and http:// www.aamc.org/meded/msop/report3.htm (for Report 3)].

JenNET, P.A. \& Swanson, R.W. (1994) Lifelong, self-directed learning: why physicians and educators should be interested, fournal of Continuing Education in Health Professions, 14, pp. 69-74.

KNowles, M. (1975) Self-Directed Learning: A Guide for Learners and Teachers (New York, Association Press).

Longworth, N. \& Davies, W.K. (1996) Lifelong Learning: New Visions, New Implications, New Roles for Industry, Government, Education and the Community in the 21st Century (London, Kogan Page).

Mennin, S.P., Kalishman, S., Friedman,M., Pathak, D. \& Snyder, J. (1996) A survey of graduates in practice from the University of New Mexico's conventional and community-oriented, problem-based tracks, Academic Medicine, 71, pp. 1079-1089.

McGowan, J.J. (1995). The role of health sciences librarians in the teaching and retention of knowledge, skills, and attitudes of lifelong learning, Bulletin of the Medical Library Association, 83, pp. 184-189.

MCKenZIE, P. (2001) How to make lifelong learning a reality: implications for the planning of educational provision in Australia, in: D. Aspin, J. Chapman, M. Hatton \& Y. Sawano (Eds) International Handbook of Lifelong Learning, 1, pp 367-378 (London, Kluwer).

Miflin, B.M., Campbell, C.B. \& Price, D.A. (1999) A lesson from the introduction of a problem-based, graduate entry course: the effects of different views of self-direction, Medical Education, 33, pp. 801-807.

Nelson, A.R. (1998) Medicine: business or professionalism, art or science?, American fournal of Obstetrics \& Gynecology, 174, pp. $755-758$.

ODDI, F. (1986) Development and validation of an instrument to identify self-directed continuing learners, Adult Education Quarterly, 36, pp. $97-107$.

ODDI, F. (1990) Construct validity of the Oddi continuing learning inventory, Adult Education Quarterly, 40, pp. 139-145.

Reiter-Palmon, R. Connelly, M.S. (2000) Item selection counts: a comparison of empirical key and rational scale validities in theory-based and non-theory-based item pools, fournal of Applied Psychology, 85, pp. 143-151.

SснміDт, H.G. (2000) Assumptions underlying self-directed learning may be false, Medical Education, 34, pp. 243-245.

SIX, J. (1989) The generality of the underlying dimensions of the Oddi continuing learning inventory, Adult Education Quarterly, 40, pp. 43-51. 